\title{
Electromigration in the Flip Chip Solder Joint of Sn-8Zn-3Bi on Copper Pads
}

\author{
W.H. LIN,$^{1,2}$ ALBERT T. WU, ${ }^{3,5}$ S.Z. LIN, ${ }^{1}$ T.H. CHUANG,${ }^{1}$ and K.N. TU ${ }^{4}$ \\ 1.-Department of Materials Science and Engineering, National Taiwan University, Taipei 106, \\ Taiwan. 2.-Present Address: Phoenix Precision Technology Corp, HsinChu 304, Taiwan. \\ 3.-Institute of Materials Science and Engineering, National Taipei University of Technology, \\ Taipei 106, Taiwan. 4.-Department of Materials Science and Engineering, UCLA, Los Angeles, \\ CA 90095-1595, USA. 5.—e-mail: atwu@ntut.edu.tw
}

Electromigration in $\mathrm{Sn}-8 \mathrm{Zn}-3 \mathrm{Bi}$ flip chip solder bumps on $\mathrm{Cu}$ pads has been studied at $120^{\circ} \mathrm{C}$ with an average current density of $4 \times 10^{3} \mathrm{~A} / \mathrm{cm}^{2}$ and $4.5 \times 10^{4} \mathrm{~A} / \mathrm{cm}^{2}$. Due to the polarity effect, the thickness of the intermetallic compound $\mathrm{Cu}-\mathrm{Zn}$ ( $\gamma$-phase) formed at the anode is much greater than that at the cathode. The solder joint fails after $117 \mathrm{~h}$ of stressing at $4.5 \times 10^{4} \mathrm{~A} / \mathrm{cm}^{2}$, and void formation at the cathode can clearly be seen after polishing. However, it is the melting at the edge of the bump that causes the solder joint to fail. A simulation of the current density distribution indicates that the current density is not distributed uniformly, and current crowding occurs inside the bump. The results indicate that the increase of current density associated with Joule heating has affected melting and enhanced damage in the solder joint during electromigration.

Key words: Sn-8Zn-3Bi, electromigration, flip chip, current crowding, Joule heating

\section{INTRODUCTION}

In the trend of device miniaturization, the dimension of features in packaging technology are becoming smaller. Recently, the bond-pad size on a substrate is down to $100 \mu \mathrm{m}$ and the damage caused by electromigration has received much attention. ${ }^{1,2}$ Many experiments have been performed to study the electromigration mechanism and damage in $\mathrm{Al}$ and $\mathrm{Cu}$ lines. ${ }^{3}$ Some experiments have also been conducted to investigate the problem of electromigration in solder joints in flip chip packaging under high current densities. ${ }^{4-6}$ Thermal effects also influence the design of devices because of the higher work efficiency and the decreasing width of the conduction line and diameter of solder bumps. Undoubtedly, electromigration plays a crucial role in the reliability in the flip chip package. ${ }^{7}$ In addition, because $\mathrm{Pb}$ will be expunged from the

(Received October 24, 2006; accepted February 18, 2007; published online June 7, 2007) solder joints due to environmental concerns, the electromigration behavior of $\mathrm{Pb}$-free solder joint is very important.

Sn-8Zn-3Bi solder is one of the lead-free solders that have been used in electronic products by industrial companies. It has a rather low melting point of $197^{\circ} \mathrm{C},{ }^{8}$ which is lower than most of the Snbased Pb-free solders. It also has the advantage of low cost and good mechanical properties in tensile test and shear test. ${ }^{9}$ Additionally, the interfacial reaction of intermetallic compound formation is different between $\mathrm{Sn}-\mathrm{Zn}-\mathrm{Bi}$ solder and $\mathrm{Cu}$ from the traditional $\mathrm{Sn}-\mathrm{Pb}$ solder or other $\mathrm{Pb}$-free solders. ${ }^{10}$ The intermetallic compound of $\mathrm{Cu}-\mathrm{Zn}(\gamma)$ forms instead of $\mathrm{Cu}_{6} \mathrm{Sn}_{5}$ and $\mathrm{Cu}_{3} \mathrm{Sn}$ at the interface between the $\mathrm{Sn}-8 \mathrm{Zn}-3 \mathrm{Bi}$ solder and $\mathrm{Cu}$ substrate. ${ }^{11}$

In this study, flip chip solder joints of Sn-8Zn-3Bi on $\mathrm{Cu}$ pads have been investigated at $120^{\circ} \mathrm{C}$ with current density of $4 \times 10^{3} \mathrm{~A} / \mathrm{cm}^{2}$ and $4.5 \times 10^{4}$ $\mathrm{A} / \mathrm{cm}^{2}$ for electromigration damage. Symmetric structures of the samples with the solder bump sandwiched between two Si substrates were used. The benefit of the symmetric structure is to be used 
to observe the effect of polarity on microstructure evolution of the solder bump, the $\mathrm{Cu}$ layer, and the intermetallic compound formation under electromigration. Because the current density plays an important role in the electromigration damage, ${ }^{12}$ a simulation was included in this study to understand the influence of current density distribution and to verify the location of the failure inside the solder joint.

\section{EXPERIMENTAL}

The samples were prepared to have the solder bump sandwiched between two Si substrates. By using lithographic methods, a thin film $\mathrm{Ta} / \mathrm{Cu}$ $(500 \AA / 10,000 \AA)$ line of $150-\mu \mathrm{m}$ width was patterned on the chip die of the oxidized Si wafer. The under-bump metallization (UBM) on the chip side was electroplated $\mathrm{Cu}(\mathrm{EP} \mathrm{Cu})$ with dimensions of $150 \mu \mathrm{m}(\mathrm{L}) \times 150 \mu \mathrm{m}(\mathrm{W}) \times 5 \mu \mathrm{m}(\mathrm{H})$. The solder bumps were electroplated Sn-8Zn-3Bi alloy and covered by rosin mildly activated (RMA) flux. After assembling the sandwiched samples, reflow of the samples in a belt furnace was conducted with a pick temperature of $230^{\circ} \mathrm{C}$ and the time above liquidus was 86 sec. A schematic diagram of the cross section of the sandwiched sample is shown in Fig. 1.

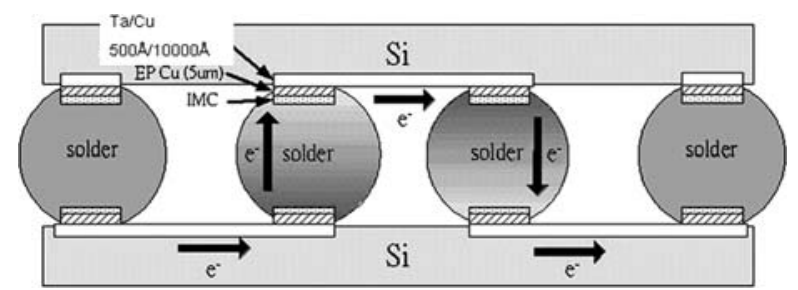

Fig. 1. A schematic diagram of the cross section of the sandwiched solder bump sample.
The samples were then cross sectioned by cutting across the center of the solder bump and polished mechanically and chemically before current stressing. The cross-sectioned area of the contact window for current density calculation became $150 \mu \mathrm{m}$ (L) $\times 50 \mu \mathrm{m}(\mathrm{W})$. Samples were stressed under current density of $4 \times 10^{3} \mathrm{~A} / \mathrm{cm}^{2}$ and $4.5 \times 10^{4} \mathrm{~A} / \mathrm{cm}^{2}$ at ambient temperature of $120^{\circ} \mathrm{C}$ for various periods of time. After electrical stressing, scanning electron microscopy (SEM) and energy-dispersive $\mathrm{x}$-ray spectroscopy (EDX) were used to observe the microstructure change of the solder bumps and the composition of the intermetallic compound under electromigration.

A two-dimensional simulation model was used to investigate the current density distribution in the sandwiched solder joints. The current went from the $\mathrm{Cu}$ line through the electroplated $\mathrm{Cu}$ UBM and intermetallic compound and into the solders. For comparison, simulations were carried out at the initial stage and also at the moment before failure when voids had propagated along the interface at the cathode.

\section{RESULTS}

The cross-sectional microstructure of a sample after the reflow is shown in Fig. 2a. The platelike Zn-rich precipitates (shown as the black color phase) embedded in the $\beta$-Sn matrix (gray). The EDX result showed that the 3 wt.\% of $\mathrm{Bi}$ had dissolved into the solder matrix. Intermetallic compound formed between the copper and solder after the reflow. The EDX indicated that the composition of the intermetallic compound (IMC) was $\mathrm{Cu}: \mathrm{Zn}: \mathrm{Sn}=34.2: 65.3: 0.5$, which indicated a $\mathrm{Cu}-\mathrm{Zn}$ system of the $\mathrm{Cu}_{5} \mathrm{Zn}_{8}(\gamma)$ phase. ${ }^{13}$
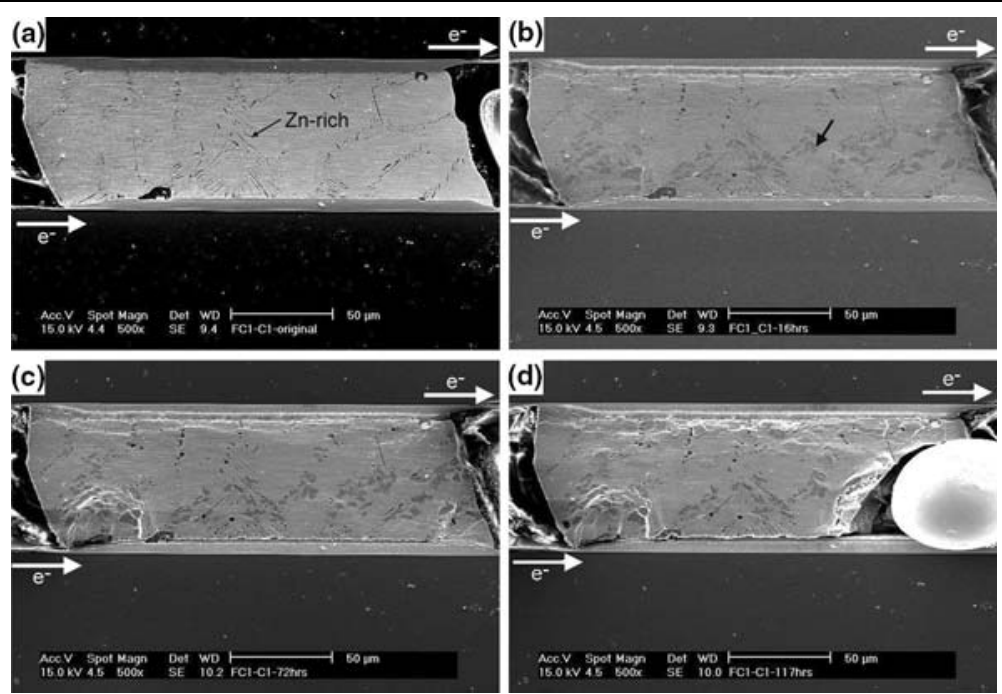

Fig. 2. Cross-sectional secondary electron images of electromigration failure of a flip chip solder joint under average current density of $4.5 \times 10^{4} \mathrm{~A} / \mathrm{cm}^{2}$ at $120^{\circ} \mathrm{C}$ : (a) before current stressed, (b) after $16 \mathrm{~h}$, (c) after $72 \mathrm{~h}$, and (d) after $117 \mathrm{~h}$. 

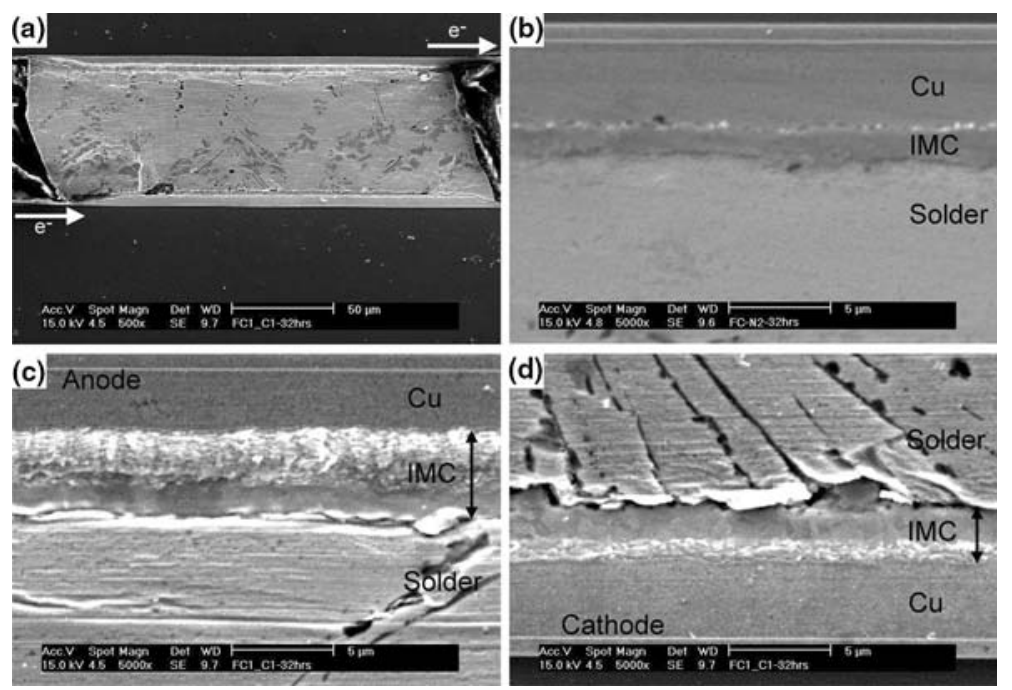

Fig. 3. Secondary electron images of the intermetallic compound at $120^{\circ} \mathrm{C}$ after $32 \mathrm{~h}$ : (a) the solder joint, (b) without current stressed, (c) with current stressed at the cathode, and (d) with current stressed at the anode.

Figure $2 b-d$ are SEM images of the cross sections of a solder bump at different times under an average current density of $4.5 \times 10^{4} \mathrm{~A} / \mathrm{cm}^{2}$ at $120^{\circ} \mathrm{C}$. In this bump, the electrons went upward from the lower left corner through the solder bump and came out from the upper right corner. After $16 \mathrm{~h}$ of electromigration testing, more IMC formation was observed compared to the sample with thermal annealing only. These IMCs were indicated by arrows, as can be seen in Fig. 2b. In Fig. 2c, after $72 \mathrm{~h}$, a crack could be observed at the cathode side of the solder. As in Fig. 7c, the inserted figure shows an enlarged schematic image of the cathode and the crack. This is the location where a high current density occurs due to current crowding. In Fig. 2d, a spheroid (in bright color) was formed at the lower right corner.

After $32 \mathrm{~h}$, Fig. $3 \mathrm{a}$ shows the electromigration damage in the lower left corner of the solder bump. Figure $3 b$ was the secondary electron image of the IMC without electromigration at $120^{\circ} \mathrm{C}$ for the same aging time. Figure $3 \mathrm{c}$ and $\mathrm{d}$ show the enlarged secondary cross-sectioned electron images on the anode and cathode side of the solder bump, respectively. They indicated the morphologies of the IMC after $32 \mathrm{~h}$ under electromigration. In both images, there were layers being squeezed out between the $\mathrm{Cu}$ UBM and solder bumps. The EDX showed that the composition of these layers was $\mathrm{Cu}-\mathrm{Zn}(\gamma)$. The thickness of the IMC is thicker at the anode side than that at the cathode side.

Figure 4a was the backscattered electron image showing that there were two distinct phases in the intermetallic compound of $\mathrm{Cu}-\mathrm{Zn}(\gamma)$. Figure $4 \mathrm{~b}$ shows the enlarged backscattered image of the IMC without electromigration. Figure 4c was the enlarged image of the anode side of the solder ball. The EDX results indicated that the composition of the gray area, region 2, was the $\mathrm{Cu}-\mathrm{Zn}$ ( $\gamma$-phase) intermetallic compound, but the white area, region 1 , was a phase rich in Sn. Figure 4d was the enlarged image at the cathode side. This shows that the phase separation in the cathode side is not as obvious as in the anode side. The squeezed regions, region 3 in Fig. 4c and region 5 in Fig. 4d, are the $\mathrm{Cu}-\mathrm{Zn}$ ( $\gamma$-phase) intermetallic compound, as mentioned before. The composition analyzed by EDX is shown in Table I.

The solder bump was polished after electromigration testing for $117 \mathrm{~h}$ and is shown in Fig. 5a. Voids can be clearly observed at the cathode side and were found to form along the interface between the solder and IMC. Figure 5b shows the enlarged image of the void at the cathode side. At the anode side, many white patches can be seen in the intermetallic compound, as can be seen in Fig. 5c. These areas were identified to be Sn-rich phase.

Figure $6 \mathrm{a}$ and $\mathrm{b}$ were the secondary electron images of the solder joint before and after electromigration, respectively, under an average current

Table I. The Composition of the Intermetallic Compound under Average Current Density of $4.5 \times 10^{4} \mathrm{~A} / \mathrm{cm}^{2}$ at $120^{\circ} \mathrm{C}$ for $32 \mathrm{~h}$

\begin{tabular}{|c|c|c|c|}
\hline \multirow{2}{*}{$\frac{\text { C1-32 h (at.\%) }}{\text { Region }}$} & \multicolumn{2}{|c|}{ IMC } & $\begin{array}{l}\text { Squeezed } \\
\text { IMC }\end{array}$ \\
\hline & 1 & 2 & 3 \\
\hline \multirow[t]{2}{*}{ Anode } & $\mathrm{Cu}: 1.6$ & $\mathrm{Cu}: 37.2$ & $\mathrm{Cu}: 37.0$ \\
\hline & Zn: 1.5 & Zn: 62.3 & Zn: 62.5 \\
\hline \multirow{4}{*}{$\begin{array}{l}\text { Region } \\
\text { Cathode }\end{array}$} & 4 & & 5 \\
\hline & $\mathrm{Cu}: 35.9$ & & $\mathrm{Cu}: 39.1$ \\
\hline & Zn: 63.6 & & $\mathrm{Zn}: 60.4$ \\
\hline & Sn: 0.5 & & Sn: 0.5 \\
\hline
\end{tabular}



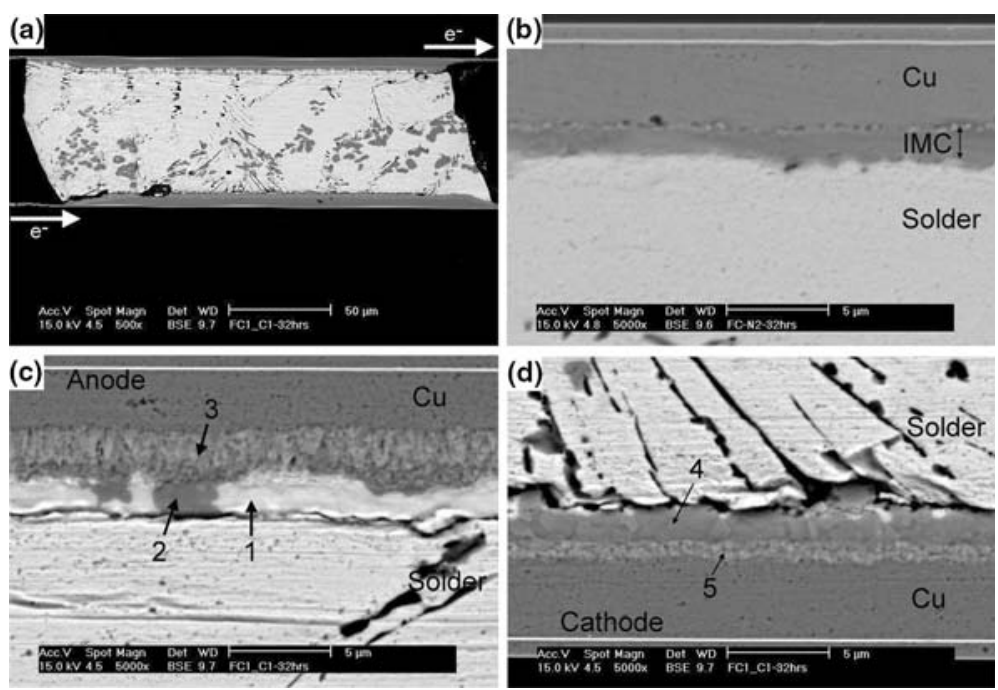

Fig. 4. Backscattered electron images of electromigration affected the intermetallic compound: (a) solder joint, (b) without current stressed, (c) interface at the anode, and (d) interface at the cathode.

density of $4 \times 10^{3} \mathrm{~A} / \mathrm{cm}^{2}$ at $120^{\circ} \mathrm{C}$ for $32 \mathrm{~h}$. It could be observed that $\mathrm{Cu}-\mathrm{Zn}(\gamma)$ had formed on both sides of the IMCs in the solder matrix and squeezed out IMC between the $\mathrm{Cu}$ UBM and solder bump. Figure $6 \mathrm{c}$ and $\mathrm{d}$ show the enlarged BSE images on the anode and cathode sides of the solder bump, respectively. The thicknesses of IMC are the same at the cathode and the anode. This indicates that there is an interfacial reaction between solder and $\mathrm{Cu}$ under an average current density of $4 \times 10^{3} \mathrm{~A} / \mathrm{cm}^{2}$ at $120^{\circ} \mathrm{C}$ for $32 \mathrm{~h}$; yet, this may be due the temperature alone, and no electromigration induced microstructure change, as shown in Fig. 4b, has occurred under this low current density condition.

To obtain the current density distribution inside the solder bump, a two-dimensional simulation was performed to investigate the effect current density distribution on void formation. A simplified map of the solder joint, which was drawn by the real structure, is shown in Fig. 7a. The simulated result is shown in Fig. 7b. The spectrum on the right-hand side of the figure indicated the normalized current density inside the solder bump.
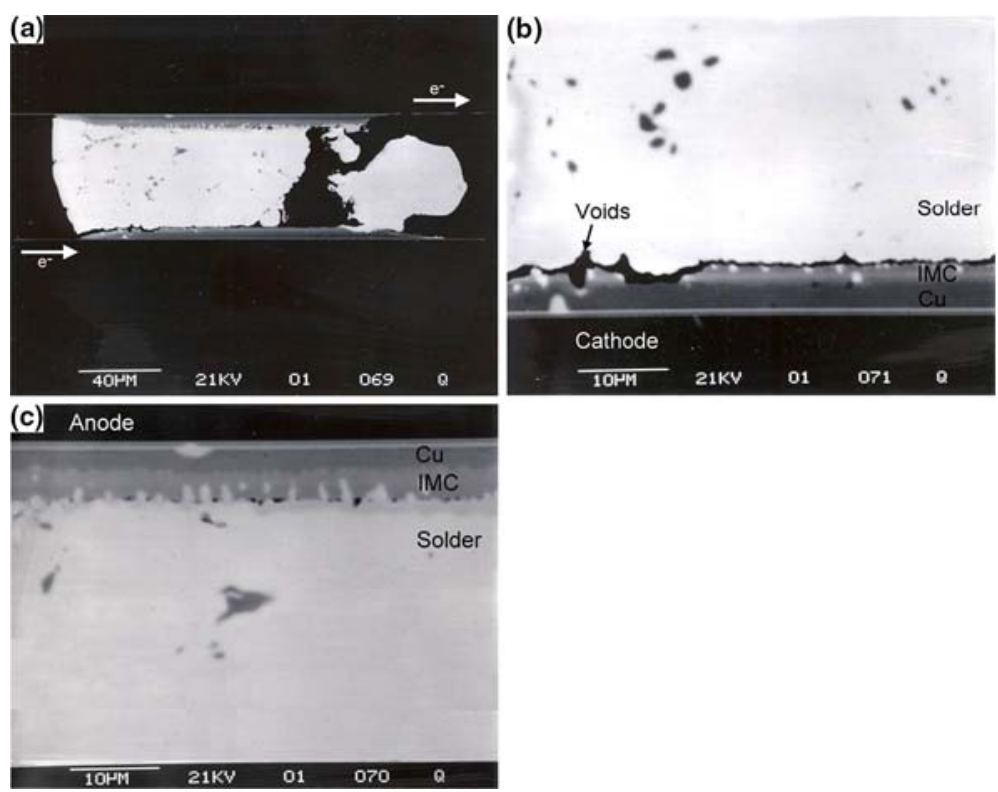

Fig. 5. Backscattered electron image of electromigration failure of the joint after polishing: (a) solder bump, (b) interface at the cathode, and (c) interface at the anode. 

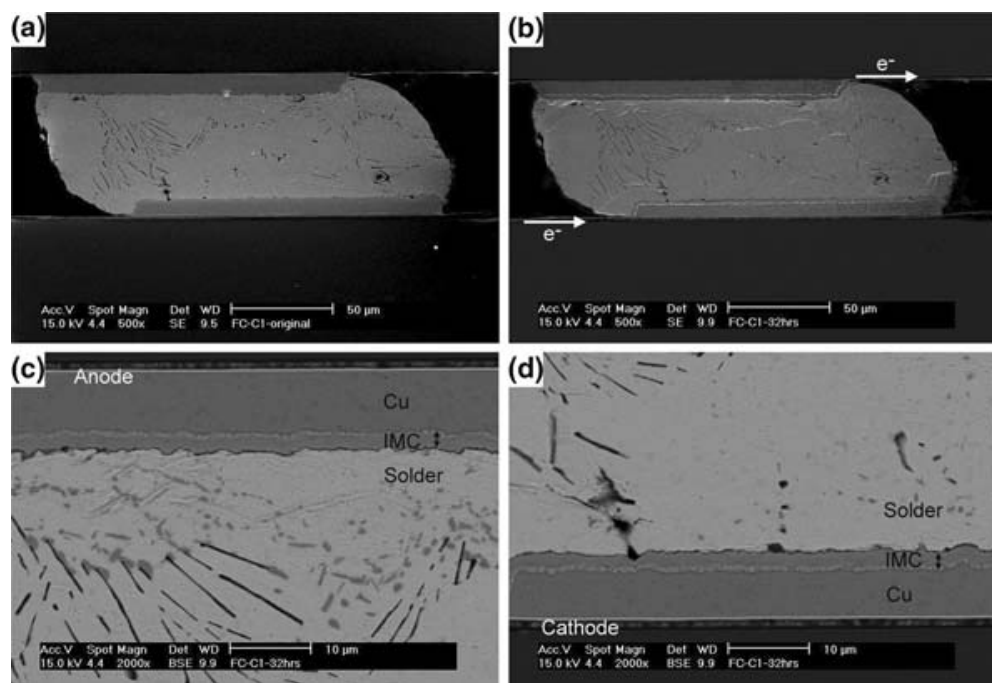

Fig. 6. Cross-sectional SEM images of the flip chip solder joint under average current density of $4 \times 10^{3} \mathrm{~A} / \mathrm{cm}^{2}$ at $120^{\circ} \mathrm{C}$ after $32 \mathrm{~h}$ : (a) secondary electron image before current stressed, (b) secondary electron image after $32 \mathrm{~h}$, (c) backscattered electron image of the interface at the anode, and (d) backscattered electron image of the interface at the cathode.
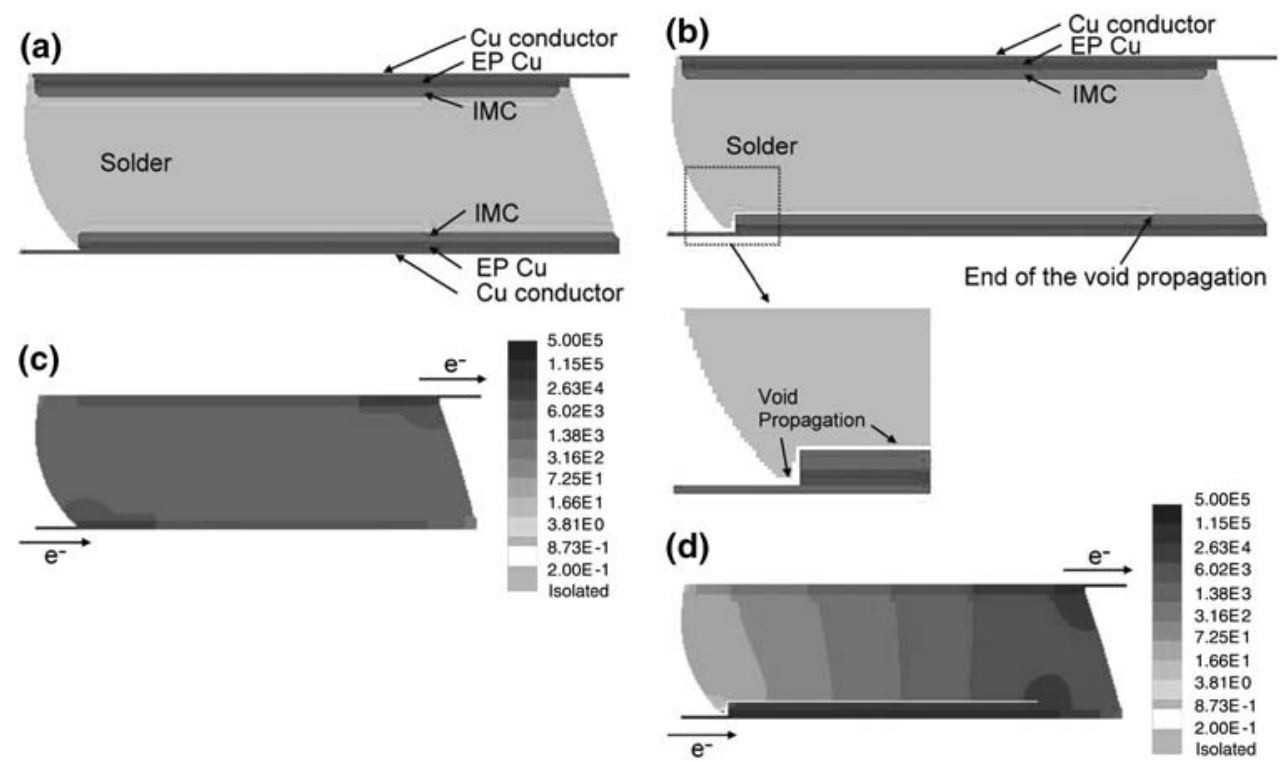

Fig. 7. The simulation of the current density distribution in the solder joint: (a) the schematic structure of the simulation at the beginning, (b) the current distribution at the beginning, (c) the schematic structure of the simulation when the void propagation was formed, and (d) the current density distribution of the voids propagated along the interface between the solder and the intermetallic compound.

The high density occurring at the lower left and upper right corner of the solder is due to current crowding from the difference in the cross section between the copper interconnect and the solder bump. Figure $7 \mathrm{c}$ is a map indicating the same solder, but a fine white gap was added between the intermetallic compound and the solder to represent the void formation at the cathode side during electromigration testing. It simulated the condition that the solder had not yet failed, but a substantial void has already formed. The simulated result in
Fig. 7d shows that the high current crowding occurs at the tip of the void.

\section{DISCUSSION}

In the $\mathrm{Sn}-\mathrm{Zn}-\mathrm{Cu}$ ternary system, the $\mathrm{Cu}-\mathrm{Zn}$ $(\gamma$-phase) compound formed at first due to the lowest free energy in the system. ${ }^{14}$ Without current stressing, a clear layer of the compound can be seen in Figs. $3 \mathrm{~b}$ and $4 \mathrm{~b}$. However, after electromigration with $4.5 \times 10^{4} \mathrm{~A} / \mathrm{cm}^{2}$ for $32 \mathrm{~h}$ at 
$120^{\circ} \mathrm{C}$, a substantial amount of $\mathrm{Sn}$ was observed between the $\gamma$-phase and solder, as can be seen in Fig. 4c. Moreover, some $\gamma$-phase patches could be seen to decorate the Sn-rich regions. Due to current stressing, both $\mathrm{Sn}$ and $\mathrm{Zn}$ atoms were pushed toward the anode. The $\mathrm{Zn}$ atoms form $\gamma$-phase right away whenever they meet copper atoms. Because $\mathrm{Zn}$ consisted of only $8 \mathrm{wt} . \%$ in the solder, it would be consumed completely by the compound formation. Furthermore, no Sn-Zn compound formed, and all the excess $\mathrm{Sn}$ accumulated at the anode side. At the cathode side, no Sn-rich phase could be found under electromigration. In Fig. 3c, $\gamma$-phase became bulged. When $\mathrm{Zn}$ atoms formed compound with $\mathrm{Cu}$, the molar volume increased. However, during the compound formation, Sn atoms also reached anode. These Sn atoms were blocked by the compound while the compound grew continuously. The growth direction of the compound was limited by the presence of Sn-rich phase. Therefore, the only way to release the extra volume would be by growing out of the plane of the free surface.

In Fig. 4c, a clear interface appeared between $\gamma$-phase and solder could be seen. Even though no Sn-Zn compound would form, we might expect to see $\mathrm{Cu}-\mathrm{Sn}$ compound $\left(\mathrm{Cu}_{6} \mathrm{Sn}_{5}\right)$ instead. However, no $\mathrm{Cu}_{6} \mathrm{Sn}_{5}$ could be seen. One plausible reason is that the annealing time interrupted to observe the cross-sectioned image was only $32 \mathrm{~h}$. The $\mathrm{Zn}$ atoms were not completely exhausted in this short period of time. Therefore, $\gamma$-phase still remained the dominant compound formed under electromigration.

In addition, Hua et al. ${ }^{15}$ found that the polarity effect in the solder joint under electromigration has a great impact on the thickness of compound formation. The compound at the cathode side dissolves into solder and reduces its thickness. On the other hand, atoms accumulated at the anode side, and a thicker compound is formed. This effect can be observed in our samples by comparing the $\gamma$-phase layers in both the anode and cathode side, as shown in Fig. $4 \mathrm{c}$ and d. The thickness of the compound at the cathode side was much less than that at the anode side.

Considering the effect of back stress, there was no depletion at the cathode side of set in short $\mathrm{Al}$ strips in Blech's electromigration experiment. ${ }^{16,17}$ Assuming back stress occurs in solder joints, the solder will not fail by electromigration if the height of the solder joint is less than the critical length $(\Delta x)$. In the equation below, $Y$ is the Young's modulus (26.6 GPa for solder ${ }^{18}$ ), $\Delta \varepsilon=0.2 \%$ is the elastic limit, $\Omega$ is the atomic volume $\left(2.7 \times 10^{-23} \mathrm{~cm}^{3}\right.$ for $\mathrm{Sn}), Z^{*}$ is the effective charge number of electromigration (about 17 for $\mathrm{Sn}), \rho$ is the resistivity $(15 \mu \Omega$ $\mathrm{cm}$ for solder), and $j$ is the current density $\left(4 \times 10^{3}\right.$ and $4.5 \times 10^{4} \mathrm{~A} / \mathrm{cm}^{2}$ ).

$$
\Delta x=\frac{Y \Delta \varepsilon \Omega}{Z^{*} e \rho j}
$$

The value of the calculated critical length is $88 \mu \mathrm{m}$ and $7.8 \mu \mathrm{m}$ at current density of $4 \times 10^{3} \mathrm{~A} / \mathrm{cm}^{2}$ and $4.5 \times 10^{4} \mathrm{~A} / \mathrm{cm}^{2}$, respectively. The height of solder joints studied here is about $60 \mu \mathrm{m}$. This finding means that the height is less than the critical length at a current density of $4 \times 10^{3} \mathrm{~A} / \mathrm{cm}^{2}$, but larger than the critical length at a current density of $4.5 \times 10^{4} \mathrm{~A} / \mathrm{cm}^{2}$. The calculated results seem to agree with the experimental observation.

Comparing Figs. $6 \mathrm{~b}$ and $3 \mathrm{a}$, there was no void formation at the cathode side of the solder joint under average current density of $4 \times 10^{3} \mathrm{~A} / \mathrm{cm}^{2}$ at $120^{\circ} \mathrm{C}$. Furthermore, not only are the thicknesses of the IMC the same at both sides of the solder, but there was no Sn-rich phase presented inside the IMC at the anode side under average current density of $4 \times 10^{3} \mathrm{~A} / \mathrm{cm}^{2}$ at $120^{\circ} \mathrm{C}$. The effect of electromigration was not obvious under this current density. The current was terminated after $200 \mathrm{~h}$ of testing and no damage was observed. Comparing to all reported electromigration studies of solders, it seems that the solder behavior is sensitive to the current density range roughly from $5 \times 10^{3}$ to $5 \times 10^{4} \mathrm{~A} / \mathrm{cm}^{2}$ at $120^{\circ} \mathrm{C}$. If the current density is lower than $5 \times 10^{3} \mathrm{~A} / \mathrm{cm}^{2}$, the electromigration effect is negligible. If the current density is higher than $5 \times 10^{4} \mathrm{~A} / \mathrm{cm}^{2}$, electromigration may lead to melting of the solder joint.

Choi et al. ${ }^{19}$ reported that the electromigration induced damage occurs when a void initiates first at the corner of the bump, where the electric current enters the bump; then, the void grows and propagates along the interface between the UBM and solder. At the same time, the formation and propagation of the voids displace the entering current to the front of the voids. The contact between the $\mathrm{Cu}$ line and the solder bump becomes open when the void has propagated across the entire contact interface. The effect can be seen in Fig. 2d, where a crack can be seen after the solder joint failed after $117 \mathrm{~h}$. Not only was a huge crack observed at the cathode side of the bump, but also a ball formed at the lower right corner. The EDX results showed that the composition of the ball was very similar to the solder. It is possible that the ball came from melting part of the solder due to joule heating. It is assumed that large joule heating in the solder bump was due to current crowding. ${ }^{20}$ When current crowding occurs at the corner where current convergence takes place, the local current density could be several times higher than the average current density. The simulation in Fig. $7 \mathrm{~b}$ shows that, indeed, at the upper right and lower left corners, the current density was about one order of magnitude higher than the average current density in the 
solder. In Fig. 2d, a spheroid could be seen at the right side of the solder. The composition was identified to be the same as the solder. This finding means that part of the solder might be melted during electromigration and resolidified afterward. The simulation result in Fig. $7 d$ indicated that the highest current density at the cathode side of the solder bump occurs at the tip of the void propagation. This place has the highest current density in the solder. Because the void is a poor heat conductor, the joule heating in the solder with a void would be much higher than that in the solder without a void.

\section{SUMMARY}

Electromigration was studied in the $\mathrm{Sn}-8 \mathrm{Zn}-3 \mathrm{Bi}$ flip chip solder bumps at a current density of $4 \times 10^{3}$ and $4.5 \times 10^{4} \mathrm{~A} / \mathrm{cm}^{2}$ at $120^{\circ} \mathrm{C}$. At the higher current density, electromigration has caused void formation and hillock growth at the cathode and anode, respectively. The thicknesses of intermetallic compounds at the anode are thicker than those at the cathode. The major intermetallic phase formed is the $\mathrm{Cu}-\mathrm{Zn}$ ( $\gamma$-phase). However, a Sn-rich phase segregated at the anode side and the bulge of the $\gamma$-phase compound could be seen.

Electromigration failed the sample at $117 \mathrm{~h}$ of testing. The failure mode showed that it is due to void formation and melting at the cathode. With the current density simulation, the failure mode showed serious current crowding after the void had propagated across the interface, and it could have increased much of the temperature by joule heating and led to melting of the solder.

\section{ACKNOWLEDGEMENT}

This study is supported by the National Science Council, Taiwan, through Grant No. NSC93-2216E002-024.

\section{REFERENCE}

1. K.N. Tu, J. Appl. Phys. 94, 5451 (2003).

2. B. Li, T.D. Sullivan, and T.C. Lee, Microelectron. Reliab. 44, 365 (2004).

3. C.S. Hau-Riege, Microelectron. Reliab. 44, 195 (2004).

4. T.Y. Lee and K.N. Tu, J. Appl. Phys. 90, 4502 (2001).

5. T.Y. Lee, K.N. Tu, S.M. Kuo, and D.R. Frear, J. Appl. Phys. 89, 3189 (2001).

6. H. Ye, C. Basaran, and D.C. Hoplins, Int. J. Solids Struct. 40, 4021 (2003).

7. P.S. Ho, G. Wang, M. Ding, J.H. Zhao, and X. Dai, Microelectron. Reliab. 44, 719 (2004).

8. Y.S. Kim, K.S. Kim, C.W. Hwang, and K. Suganuma, J. Alloys Compd. 352, 237 (2003).

9. T. Sugizaki, H. Nakao, T. Kimura, and T. Watanabe, Mater. Trans. 44, 1790 (2003).

10. K. Suganuma, Curr. Opin. Solid State Mater. Sci. 5, 55 (2001).

11. P. Harris, Surf. Mount Technol. 46 (1999).

12. E.C.C. Yeh, W.J. Choi, and K.N. Tu, Appl. Phys. Lett. 80, 580 (2002).

13. T.B. Massalski, J.L. Murray, L.H. Bennett, H. Baker, Binary Alloy Phase Diagrams (Materials Park, OH: ASM International, 1990), vol. 1, p. 981.

14. T. Jantzen and P.J. Spencer, Calphad-Comput. Coupl. Phase Diag. Thermochem. 22, 417 (1998).

15. H. Gan and K.N. Tu, J. Appl. Phys. 97, 063514-1 (2005).

16. I.A. Blech, J. Appl. Phys. 47, 1203 (1976).

17. I.A. Blech and C. Herring, Appl. Phys. Lett. 29, 131 (1976).

18. I. Shohji, T. Yoshida, T. Takahashi, and S. Hioki, J. Mater. Sci. Mater. Electron. 15, 219 (2004).

19. W.J. Choi, E.C.C. Yeh, and K.N. Tu, J. Appl. Phys. 94, 5665 (2003).

20. T.L. Shao, Y.H. Chen, S.H. Chiu, and C. Chen, J. Appl. Phys. 96, 4518 (2004). 